\title{
Dictionnaire Giono, sous la direction de Mireille SACOTTE et Jean-Yves LAURICHESSE
}

\section{Aron Verga}

\section{OpenEdition}

\section{Journals}

\section{Edizione digitale}

URL: http://journals.openedition.org/studifrancesi/16705

DOI: 10.4000/studifrancesi. 16705

ISSN: 2427-5856

\section{Editore}

Rosenberg \& Sellier

\section{Edizione cartacea}

Data di pubblicazione: 1 juillet 2019

Paginazione: 191

ISSN: 0039-2944

\section{Notizia bibliografica digitale}

Aron Verga, «Dictionnaire Giono, sous la direction de Mireille sacotte et Jean-Yves LaURichesse», Studi Francesi [Online], 187 (LXIII | I) | 2019, online dal 01 juillet 2019, consultato il 25 janvier 2021. URL: http://journals.openedition.org/studifrancesi/16705; DOI: https://doi.org/10.4000/studifrancesi. 16705

Questo documento è stato generato automaticamente il 25 janvier 2021.

\section{(c) (i) (9)}

Studi Francesi è distribuita con Licenza Creative Commons Attribuzione - Non commerciale - Non opere derivate 4.0 Internazionale. 


\title{
Dictionnaire Giono, sous la direction de Mireille SACOTTE et Jean-Yves
}

\section{LAURICHESSE}

\author{
Aron Verga
}

\section{NOTIZIA}

Dictionnaire Giono, sous la direction de Mireille SACOTTE et Jean-Yves LAURICHESSE, Paris, Classiques Garnier, 2016, «Dictionnaires et synthèses» 9, 986 pp.

1 Il Dictionnaire Giono, attraverso le sue seicentocinquantadue voci, vuole offrire una sintesi delle conoscenze e interpretazioni degli studi su Jean Giono, nonché un riflesso della vita e dell'opera dell'autore provenzale del secolo scorso. Alla stesura di questo volume hanno preso parte ventiquattro studiosi fornendo pertanto una diversità di punti di vista, di metodologie, di stili. La forma del dizionario, col suo rigido ma efficace ordine alfabetico, risponde a un bisogno di informazione e di chiarezza. I curatori ritengono sia infatti la modalità migliore per il lettore, amatoriale o specialista, alla ricerca di un tema, di una nozione, di un luogo, di un personaggio legati a questa figura letteraria. In aiuto al lettore, al fine di orientarlo al meglio e di offrire maggiore profondità alle singole parole ricercate, sono presenti diversi simboli: gli asterischi, all'interno del testo, e le frecce, al termine della voce, segnalano rinvii ad altre voci presenti nel dizionario; i triangoli neri forniscono dei rimandi bibliografici e permettono un aggiornamento delle ultime produzioni della critica.

2 La moltitudine di schede permette di spaziare attraverso le vicende biografiche e letterarie di Jean Giono; creare percorsi tematici risulta pertanto facilitato dal sistema di rimandi studiato dai redattori di quest'opera, la cui struttura ha delle affinità con la ricerca in rete dell'epoca contemporanea, fatta di collegamenti. La poliedricità del Dictionnaire Giono permette quindi a qualsiasi lettore interessato di avvicinarvisi con relativa facilità. Peculiarità propria dei dizionari letterari è la duplice maniera di 
consultazione. Da un lato, la lettura delle singole voci al solo scopo di approfondire un tema specifico, come l'«Égoïsme» (p. 330), o le vicende di un personaggio, per esempio la scheda «Lavinia» (p. 532), figura femminile presente in Le Hussard sur le toit e in Le bonheur fou; dall'altro, la possibilità di lasciarsi trasportare dal flusso degli accorgimenti tipografici sopra menzionati, entrando così in una sorta di racconto all'interno del dizionario, senza tuttavia seguire l'ordine delle pagine. Per esempio, partendo dalla lettura della voce «Whitman, Walt» (p. 969, come Giono entrò in contatto con l'opera del poeta americano, quanto ne fu influenzato, quando se ne distaccò), si passa facilmente a «Melville, Herman» (p. 577) e a Moby Dick, per poi far idealmente ritorno in Francia con le schede «Manosque» (p. 561) e «Colline» (p. 221, quelle provenzali che prendevano le sembianze delle onde oceaniche mentre Giono leggeva le avventure dell'equipaggio del Pequod).

Un altro percorso interessante si può seguire partendo dalla voce «Italie» (p. 488), dove il nonno dello scrittore nacque in un paesino delle Alpi piemontesi, costretto poi all'esilio in Francia per sfuggire alla polizia austriaca. Il padre di Giono, nato invece in Francia, narrava tuttavia storie dell'Italia e del nonno dell'autore: tutto questo contribuì a creare un mondo favoloso e romanzesco alla base del "Cycle du Hussard» (p. 262). L'Italia è spesso presente nell'opera di Jean Giono, sotto forme differenti, come ricordi, cartine appese alle pareti delle stanze, ma anche nelle persone emigrate a Marsiglia e nel resto della Provenza. Giono, quanto a lui, visitò l'Italia solo alcuni anni dopo la Seconda guerra mondiale e pubblicò diversi testi su varie riviste al riguardo, testi poi raccolti in volume nel 1954, «Voyage en Italie» (p. 963). Leggendo questa voce si può scoprire come l'Italia di quegli anni fosse meta anche di altri scrittori francesi, $\mathrm{i}$ quali scrissero a loro volta dei racconti di viaggio. Tra questi vi era anche «Sartre» (p. 841). I due non si incontrarono mai, erano divisi pressoché su tutto, benché inizialmente si fossero scambiati complimenti reciproci: Giono voleva trarre una sceneggiatura dalla Nausée, mentre Sartre scrisse delle parole di elogio nei suoi Carnets de la drôle de guerre. Tuttavia con il passare del tempo le distanze divennero sempre più incolmabili, in particolare dopo l'articolo di Sartre «Pour saluer Melville» (p. 750), un breve testo che doveva accompagnare la traduzione di Giono di Moby Dick. Alla voce «Traductions» (p. 912) possiamo apprendere come lo scrittore provenzale avesse in cantiere diverse opere tradotte, ma soltanto quella del capolavoro di Melville venne pubblicata nel 1941 ed era la prima volta che il romanzo appariva in lingua francese. 